\title{
Assesment of the heart volume using computerized tomography and magnetic resonance imaging
}

\author{
Fikri Ozdemir ${ }^{a^{*}}$, Micheal Mazonakis ${ }^{\mathrm{b}}$, Bunyamin Sahin ${ }^{\mathrm{a}}$, Amani Elfaki ${ }^{\mathrm{a}}$, Ozcan Yilmaz ${ }^{\mathrm{c}}$, Mustafa Bekir Selcuk $^{\mathrm{d}}$ \\ ${ }^{a}$ Deparment of Anatomy, Faculty of Medicine, Ondokuz Mayis University, Samsun, Turkey \\ ${ }^{b}$ Department of MedicalPhysics, Faculty of Medicine, University of Crete, Iraklion Crete, Greece \\ ${ }^{c}$ Depermant of Cardiology, Faculty of Medicine, Ondokuz Mayis University, Samsun, Turkey \\ ${ }^{d}$ Depermant of Radiology, Faculty of Medicine, Ondokuz Mayis University, Samsun, Turkey
}

\section{ARTICLE INFO \\ ABSTRACT}

\section{* Correspondence to: \\ Fikri Özdemir \\ Deparment of Anatomy, \\ Faculty of Medicine, \\ Ondokuz Mayis University, \\ Samsun, Turkey \\ e-mail:fikri.ozdemir@omu.edu.tr}

\section{Keywords:}

Computarized tomography image

Magnetic resonance image

Threshold

Planimetry

Ventricular volume
Heart volume along with dose volume histograms are essential in reducing pulmonary and cardiac complications. The aim of this study is to measure the ventricular volume using computerized tomography (CT) and magnetic resonance imaging (MRI), to detect the differences between the two scans and to investigate whether the estimated volumes concur with the actual volume of the hearts obtained by the fluid displacement technique. The present study were performed in six heart sheep. Hearts were scanned in the horizontal plane using CT (Toshiba, Aquilion, Japan) and MR machine (Siemens 1.5T Avanto, Germany), we decided for $1 \mathrm{~mm}$ as sample thickness fraction for both MR and CT images.The images were analyzed using Image software. Planimetry and threshold stereological methods were applied to estimate the ventricular volume. To evaluate the accuracy of two scans, all the estimates were done by the same observer. The actual hearts mean volumes were $109.38 \mathrm{~cm}^{3} \pm 17.77$. The mean volume of the hearts in CT images of different thickness $(0.94,1.94,2.94,3.94$ and $4.94 \mathrm{~mm})$ were $110.34 \mathrm{~cm}^{3} \pm 17.63,110.61$ $\mathrm{cm}^{3} \pm 17.70,111.03 \mathrm{~cm}^{3} \pm 17.65,111.48 \mathrm{~cm}^{3} \pm 17.68$ and $112.18 \mathrm{~cm}^{3} \pm 17.86$, respectively. The mean volume of the hearts in MRI of different thickness $(1.1,2.1,3.1,4.1$ and 5.1 $\mathrm{mm})$ were $103.78 \mathrm{~cm}^{3} \pm 17.60,104.12 \mathrm{~cm}^{3} \pm 17.91,104.31 \mathrm{~cm}^{3} \pm 17.89,104.41 \mathrm{~cm}^{3} \pm 17.84$ and $104.56 \mathrm{~cm}^{3} \pm 17.95$, respectively. There were significant statistical difference between the mean volume of the actual hearts and mean volume of the hearts in CT and MRI $(p<0.05)$. CT and MRI datasets allowed an interchangeable utilization of volumetric analysis tools, MRI demonstrated a significant reduction in the ventricular volume, while CT provides accurate volumetric information of the ventricles in comparison withactual hearts volume. However, reliable volumetric analysis was limited to an optimal range of cardiac rates for each modality.

J. Exp. Clin. Med., 2014; 31:146 